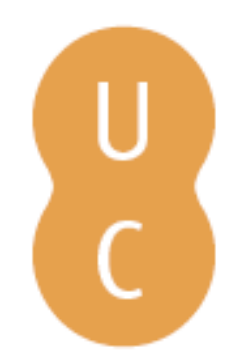

\title{
pommalina
}

\section{Três representações quinhentistas da utopia na Literatura Portuguesa}

\author{
Autor(es): $\quad$ Moniz, António Manuel de Andrade
}

Publicado por: Imprensa da Universidade de Coimbra

URL

persistente: $\quad$ URI:http://hdl.handle.net/10316.2/32069

DOI: $\quad$ DOI:http://dx.doi.org/10.14195/978-989-26-0499-2_18

Accessed : $\quad$ 26-Apr-2023 15:00:06

A navegação consulta e descarregamento dos títulos inseridos nas Bibliotecas Digitais UC Digitalis, UC Pombalina e UC Impactum, pressupõem a aceitação plena e sem reservas dos Termos e Condições de Uso destas Bibliotecas Digitais, disponíveis em https://digitalis.uc.pt/pt-pt/termos.

Conforme exposto nos referidos Termos e Condições de Uso, o descarregamento de títulos de acesso restrito requer uma licença válida de autorização devendo o utilizador aceder ao(s) documento(s) a partir de um endereço de IP da instituição detentora da supramencionada licença.

Ao utilizador é apenas permitido o descarregamento para uso pessoal, pelo que o emprego do(s) título(s) descarregado(s) para outro fim, designadamente comercial, carece de autorização do respetivo autor ou editor da obra.

Na medida em que todas as obras da UC Digitalis se encontram protegidas pelo Código do Direito de Autor e Direitos Conexos e demais legislação aplicável, toda a cópia, parcial ou total, deste documento, nos casos em que é legalmente admitida, deverá conter ou fazer-se acompanhar por este aviso.

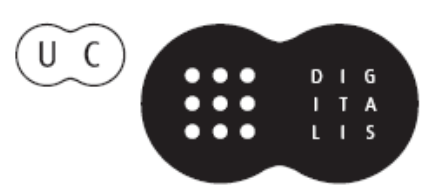


Maria de Fátima Silva

Coordenação

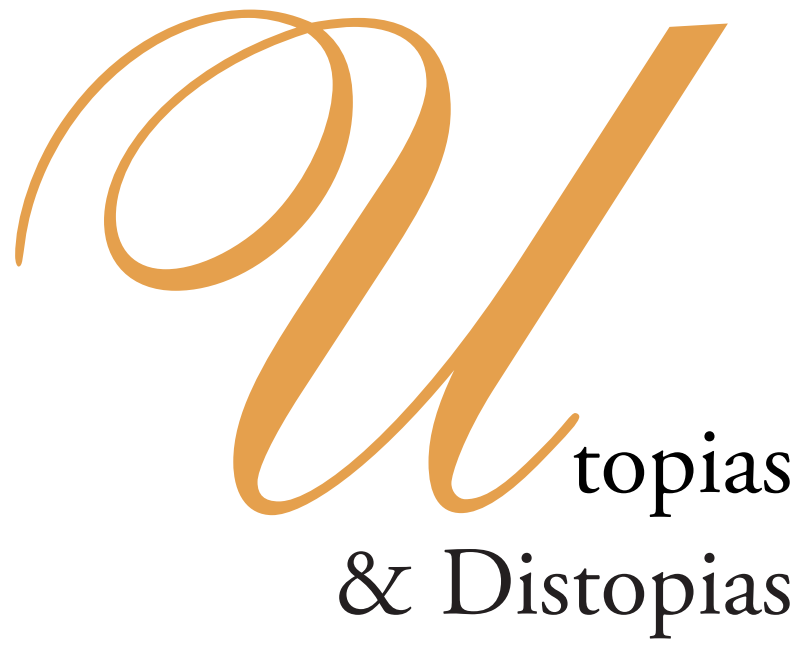




\section{COORDENAÇÃO EDITORIAL \\ Imprensa da Universidade de Coimbra \\ Email: imprensauc@ci.uc.pt \\ URL: http://www.uc.pt/imprensa_uc}

\section{CONCEPÇÃO GRÁFICA}

António Barros

Pré-IMPRESSÃo

Tipografia Lousanense, Lda.

EXECUÇÃO GRÁFICA

Tipografia Lousanense, Lda.

ISBN

978-989-8074-74-4

DEPósito LEGAL

289002/09

OBRA PUBLICADA COM O APOIO DE:

Centro de Estudos Clássicos e Humanísticos

Faculdade de Letras da Universidade de Coimbra

FCT Fundação para a Ciência e a Tecnologia

MINISTÉRIO DA CIÊNCIA, TECNOLOGIA E ENSINO SUPERIOR Portugal 
Maria de Fátima Silva

Coordenação
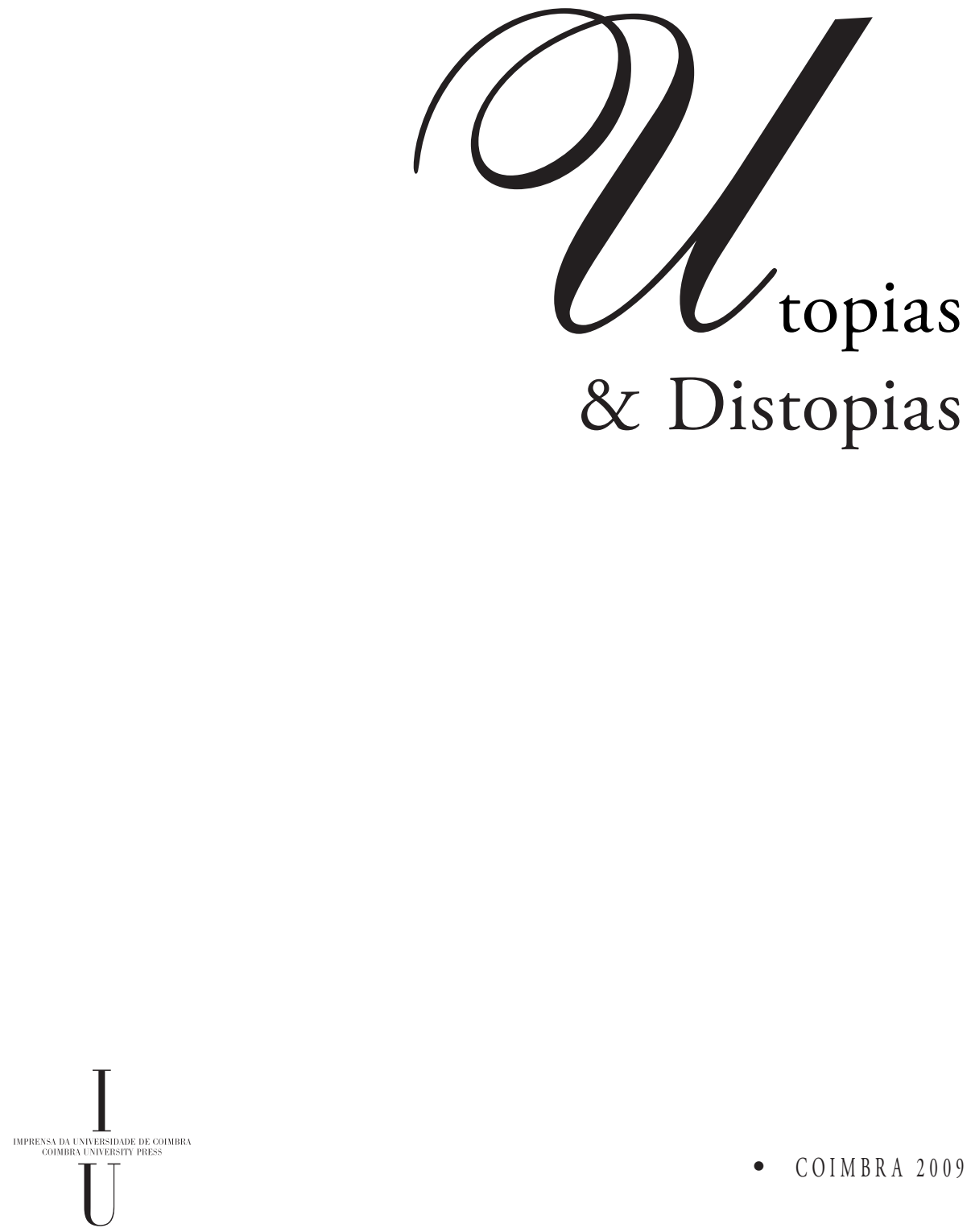

- colmbra 2009 



\section{TRÊS REPRESENTAÇÕES QUINHENTISTAS \\ DA UTOPIA NA LITERATURA PORTUGUESA}

\section{Introdução}

O mundo clássico, sensível ao arquétipo idealista da vocação humana, representou, talvez como nenhum outro, a tela dourada da utopia. As suas representaçóes míticas, na Odisseia, como a dos Campos Elísios ${ }^{1}$, a gruta de Calipso ${ }^{2}$, os jardins de Alcínoo, na ilha dos Feaces $^{3}$, bem como a hesiódica idade de ouro ${ }^{4}$, a platónica Atlântida e sua República, ou mesmo os Idílios bucólicos, de Teócrito, são eloquentes expressôes desse arquétipo. Entre os Romanos, podemos salientar as Bucólicas, de Virgílio, designadamente a IV, a simbologia do mundo das abelhas ${ }^{5}$, nas suas Geórgicas, para além dos Campos Elísios, na Eneida ${ }^{6}$, como excelentes exemplos dessa representação.

O mundo judaico-cristão, desde o mítico Éden 7 aos "novos Céus e nova Terra" do Livro do Apocalipse ${ }^{8}$, passando pela alegoria profética da paz em Isaías ${ }^{9}$, também contribuiu, de modo significativo, para a excelência dessa representaçáo.

Herdeiro, tal como a Idade Média, desse ideal, o Renascimento europeu não só criou, a partir da língua grega, a palavra que corporizaria o mundo da utopia, mas também insuflou várias das suas obras com o halo maravilhoso desse espírito.

Escolhemos três obras literárias portuguesas como expressão privilegiada do mundo utópico: Os Lusiadas, a Peregrinaçam e a História Trágico-Marítima.

\footnotetext{
1 "Aí se oferece aos homens uma vida mais fácil. / Não neva, não há grande invernia, nem chuva. / Mas as brisas do Zéfiro sopram sempre ligeiras, / vindas do Oceano, para refrescar os homens" (Od., IV, 565568), trad. de M. H. da Rocha Pereira, Hélade, 6a ed., (Coimbra, FLUC, 1995) 54.

${ }^{2}$ Cf. Od. V, 44 ss.

3 Cf. Od. VII, 112-132.

${ }^{4}$ Cf. Hesíodo, Trabalhos e Dias, 109-126.

5 Cf. Virgílio, Geórgicas, IV, 149-314.

${ }^{6}$ Cf. Aen., VI, 791-794.

7 Cf. Gén. II, 8-15.

${ }^{8}$ Ap. XXI, 1.

${ }^{9}$ Cf. Is., XI, 1-9.
} 


\section{Os Lusíadas}

Espaço mítico por excelência, a Ilha de Vénus que Camões figura algures no Índico, palma glorificadora da gesta lusa no Oriente, simboliza o arquétipo dos valores humanos e cristáos capazes de plasmarem a civilização e a cultura europeias do século XVI, ameaçada já pela sombra do materialismo económico e pela ameaça otomana.

Coroando o esforço despendido no "largo mar que navegaram"10, a deusa Cípria ordena, a "favor dos Lusitanos", "A glória por trabalhos alcançada, / Satisfação de bem sofridos danos"11, a famosa Ilha de Vénus ${ }^{12}$. Na sua descrição, os semas do deleite edénico repartem-se pela gradação de adjectivos, como fresca e bela ${ }^{13}$, alegre e deleitosa, claras e límpidas, e as metáforas decorativas, como gramíneo esmalte ${ }^{14}$, num cenário hiperbólico ${ }^{15}$ de locus amoenus ${ }^{16}$. A efusão sensorial reparte-se por cada um dos cinco sentidos, numa sinestesia capaz de envolver esteticamente o leitor: a formosura, agradável à vista ${ }^{17}$; a expansão odorífera dos frutos e das flores, captada pelo olfacto $^{18}$; a doçura dos sabores de Pomona, como a cereja, a amora, o pêssego, a romá, a uva ou a pêra ${ }^{19}$; a fina sugestáo do $\operatorname{tacto}^{20}$; o concerto harmonioso das aves canoras $^{21}$ e das belas Ninfas ${ }^{22}$.

10 "Despois de ter hum pouco revolvido / Na mente o largo mar que navegaram, / Os trabalhos que pelo Deus nascido / Nas Amphioneas Thebas se causaram, / Já trazia de longe no sentido, / Pera prémio de quanto mal passaram, / Buscar-lhe algum deleite, algum descanso, / No reino de cristal, líquido e manso" (Ib., 19).

11 "Porém a Deusa Cípria, que ordenada / Era, pera favor dos Lusitanos, / Do Padre eterno, e por bom génio dada, / Que sempre os guia já de longos anos, / A glória por trabalhos alcançada, / Satisfação de bem sofridos danos, / Lhe andava já ordenando, e pretendia / Dar-lhe nos mares tristes alegrias" (Ib., 18).

12 "Cortando vão as naus a larga via / Do mar ingente pera a pátria amada, / Desejando prover-se de água fria, / Pera a grande viagem prolongada, / Quando, juntas, com súbita alegria, / Houveram vista da ilha namorada, / Rompendo pelo céu a mãe fermosa / De Menónio, suave e deleitosa” (Ib., 51).

13 "De longe a Ilha viram, fresca e bela, / Que Vénus pelas ondas lha levava" (Ib., 52, 1-2).

14 "Três fermosos outeiros se mostravam, / Erguidos com soberba graciosa, / Que de gramíneo esmalte se adornavam, / $\mathrm{Na}$ fermosa ilha alegre e deleitosa. / Claras fontes e límpidas manavam / Do cume, que a verdura tem viçosa; / Por entre pedras alvas se diriva / A sonorosa linfa fugitiva” (Ib., 54).

15 "Tão bela quanto pode imaginar-se" $(I b ., 55,4)$.

16 "Num vale ameno, que os outeiros fende, / Vinham as claras águas ajuntar-se, / Onde hia mesa fazem, que se estende / Tão bela, quanto pode imaginar-se. / Arvoredo gentil sobre ela pende, / Como que pronto está pera afeitar-se, / Vendo-se no cristal resplandecente, / Que em si o está pintando propriamente" (Ib., 55).

17 Cf. Ib., 54 e 55.

18 "Mil árvores estão no céu subindo, / Com pomos odoríferos e belos; / A laranjeira tem no fruito lindo / A cor que tinha Daphne nos cabelos, / Encosta-se no chão, que está caindo, / A cidreira cos pesos amarelos; / Os fermosos limôes, ali cheirando, / Estão virgíneas tetas imitando” (Ib., 56). Cf. Ib., 60-62.

19 "Os dóes que dá Pomona ali natura / produze diferentes nos sabores, / Sem ter necessidade de cultura, / Que sem ela se dão muito milhores: / As cerejas, purpúreas na pintura, / As amoras, que o nome tem de amores, / O pomo que da pátria Pérsia veio, / Milhor tornado no reino alheio. // Abre a romã, mostrando a rubicunda / Cor, com que tu, rubi, teu preço perdes; / E vós, se na vossa árvore fecunda, / Peras piramidais, viver quiserdes, / Entregai-vos ao dano que, cos bicos, / Em vós fazem os pássaros inicos" (Ib.,59.60).

20 "Pois a tapeçaria bela e fina, / Com que se cobre o rústico terreno, / Faz ser a de Acheménia menos dina, / Mas o sombrio vale mais ameno. / Ali a cabeça a flor Cyfísia inclina, / Sôbolo tanque lúcido e sereno” (Ib., 60, 1-6).

21 "Pois, se as aves no ar cantando voam, / Alegres animais o chão povoam. // A longo da água o níveo cisne canta, / Responde-lhe do ramo Philomela" (Ib., 62, 7-8. 63, 1-2).

22 "Algias, doces cítaras tocavam, / Algias harpas e sonorosas frautas; Outras, cos arcos de ouro, se fingiam / Seguir os animais, que não seguiam” (Ib., 64, 5-8). 
Num ambiente de fantástica sedução ${ }^{23}$, instaura-se a dúvida entre o real e o imaginário ${ }^{24}$; anima-se uma cena de perseguição sexual ${ }^{25}$; transcreve-se uma interpelação de Leonardo, "Manhoso, cavaleiro e namorado" 26 a "Efire, exemplo de beleza, / Que mais caro que as outras dar queria / O que deu pera dar-se a natureza" 27 ; consumase, enfim, o "puro amor" 28 , para se proceder à solene coroaçáo dos heróis ${ }^{29}$.

Num gesto de privilegiada revelação, a deusa Tétis conduz o Capitão luso ao "cume dum monte alvo e divino" 30 , "Pera lhe descobrir da unida esfera / Da terra imensa e mar não navegado / Os segredos, por alta profecia, / O que esta sua naçáo só merecia" ${ }^{1}$. Assim, quase todo o canto X se ocupará do objecto de tal revelaçáo proléptica: o nome e as conquistas dos heróis nacionais ${ }^{32}$; a explicação da grande máquina do mundo ${ }^{33}$, da qual fazem parte a Europa crista ${ }^{34}$, a África, dos bens do mundo avara, / Inculta e toda cheia de bruteza $a^{35}$, a Ásia, "Em terras grande, em reinos opulenta" 36 , a América, "a grande terra que contina / Vai de Calisto ao seu contrário Polo" 37.

Mas esta Ilha, "que nas entranhas do profundo / Oceano", "De dões de Flora e Zéfiro adornada"38, "com mil deleites não vulgares"39 é aparelhada por Vénus, mais não é do que um episódio alegórico da glorificação épica dos navegadores lusitanos ${ }^{40}$,

23 "Começam de enxergar subitamente, / Por entre verdes ramos, várias cores, / Cores de quem a vista julga e sente / Que não eram das rosas ou das flores, / Mas da lá fina e seda diferente, / Que mais incita a força dos amores, / De que se vestem as humanas rosas, / Fazendo-se por arte mais fermosas" (Ib., 68).

24 “Sigamos estas Deusas e vejamos / Se fantásticas são, se verdadeiras" (Ib., 70, 1-2).

25 "Isto dito, veloces mais que gamos, / Se lançam a correr pelas ribeiras. / Fugindo as Ninfas vão por entre os ramos, / Mas, mais industriosas que ligeiras, / Pouco e pouco, sorrindo e gritos dando, / Se deixam ir dos galgos alcançando" (Ib., 70, 3-8. Cf. 71-81).

$26 \mathrm{Ib} ., 75,2$. Cf. 76-81.

$27 \mathrm{Ib}, 76,2-4$.

${ }^{28}$ Ib., 82, 8. "Oh! Que famintos beijos na floresta, / E que mimoso choro que soava! / Que afagos tão suaves, que ira honesta, / Que em risinhos alegres se tornava! / O que mais passam na manhã e na sesta, / Que Vénus com prazeres inflamava, / Milhor é experimentá-lo que julgá-lo; / Mas julgue-o quem não pode experimentá-lo" (Ib., 83).

29 "Desta arte, enfim, conformes já as fermosas / Ninfas, cos seus amados navegantes, / Os ornam de capelas deleitosas / De louro e de ouro, e de flores abundantes” (Ib., 84, 1-4).

$30 \mathrm{Ib}, \mathrm{87}, 2$.

31 Ib., 86, 5-8.

${ }^{32}$ Duarte Pacheco Pereira, D. Francisco de Almeida, Tristão da Cunha, Afonso de Albuquerque, Lopo Soares de Albergaria, Diogo Lopes de Sequeira, D. Duarte de Meneses, D. Henrique de Meneses, D. Pedro de Mascarenhas, Lopo Vaz de Sampaio, Heitor da Silveira, Nuno da Cunha, D. Garcia de Noronha, Estêvão da Gama, Martim Afonso de Sousa, D. João de Castro.

33 Ib., X, 80, 1.

$34 \mathrm{Ib} ., 92,1$.

$35 \mathrm{Ib}, 92,3$.

$36 \mathrm{Ib}, 99,7.8$.

37 Ib., 139, 1-2.

38 Ib., IX, 40, 6-8.

39 "Ali, com mil refrescos e manjares, / Com vinhos odoríferos e rosas, / Em cristalinos paços singulares, / Fermosos leitos e elas mais fermosas /; Enfim, com mil deleites não vulgares; / Os esperem as Ninfas amorosas, / De amor feridas, pera lhe entregarem / Quanto delas os olhos cobiçarem” (Ib., 41).

40 "Que as Ninfas do Oceano, tão fermosas, / Thétis e a Ilha angélica pintada, / Outra cousa nẫo é que as deleitosas / Honras que a vida fazem sublimada. / Aquelas preminências gloriosas, / Os triunfos, a fronte coroada / De palma e louro, a glória e maravilha: / Estes são os deleites desta Ilha” (Ib., 89). 
à semelhança das "imortalidades que fingia / A Antiguidade, que os ilustres ama, / [...] Por obras valerosas, que fazia" ${ }^{41}$, segundo a hermenêutica evemerista.

\section{A Peregrinaçam}

Fascinado pela civilização chinesa, Fernão Mendes Pinto, como vários peregrinantes portugueses da época (Tomé Pires, Duarte Barbosa, Fr. Gaspar da Cruz, entre outros), encontra na cidade de Pequim o expoente máximo da ordem, da justiça e da abundância, valores considerados basilares da felicidade humana, dos quais o mundo ocidental se encontrava carecido.

Apesar do testemunho visual do sujeito narrador ${ }^{42}$, vários são os historiadores ${ }^{43}$ que têm desacreditado o valor da Peregrinaçam como monumento ou memória cultural de acontecimentos, personagens e situaçôes que tocam de modo profundo uma época áurea do nosso quotidiano histórico nas remotas paragens do Extremo Oriente. Ora, a China, ocupando a parte central da obra, do capítulo XXXIX ao CXXVII, é o ponto culminante da crónica de viagens, não apenas enquanto lhe são dedicados 89 dos 226 capítulos, ou seja, 39,8\%, mas, principalmente, porque tal sociedade constitui o mais claro expoente da civilização humana, tanto oriental, como ocidental.

Lembrando, de algum modo, a oração fúnebre de Péricles, na guerra do Peloponeso, registada por Tucídides, o encómio da cidade chinesa, cujo expoente simbólico é a cidade de Pequim, representa o arquétipo de toda a actividade política, baseado na ordem e na justiça: a apologia da igualdade de todos perante a lei e a dignidade do mérito, a fruiçáo feliz da sociedade da abundância.

O capítulo CVII, "De algumas coisas particulares notáveis que há na cidade do Pequim”, apresenta-nos essa cidade, cujo nome é explicado de acordo com a tradição mitológica ${ }^{44}$, como a concretização do arquétipo que classificara como metrópole da monarquia do Mundo ${ }^{45}$. Assim, as maiores metrópoles ocidentais, segundo uma ordem provavelmente hierarquicamente descendente ${ }^{46}$, bem como as grandes capitais orientais ${ }^{47}$ são colocadas em posição nitidamente inferior ${ }^{48}$.

41 "Que as imortalidades que fingia / A Antiguidade, que os ilustres ama, / Lá no estelante Olimpo a quem subia / Sobre as asas ínclitas da Fama, / Por obras valerosas, que fazia, / Pelo trabalho imenso, que se chama / Caminho da virtude, alto e fragoso, / Mas, no fim, doce, alegre e deleitoso; // Náo eram senão prémios que reparte, / Por feitos imortais e soberanos, / $\mathrm{O}$ mundo cos varóes que esforço e arte / Divinos os fizeram, sendo humanos" (Ib., 90. 91, 1-4).

42 “[... quero eu declarar a causa desta dúvida conforme ao que vi por meus olhos" (cap. CV).

${ }^{43} \mathrm{Na}$ esteira de G. Le Gentil, V. M. Godinho póe em dúvida a presença de Fernão Mendes Pinto na China (cf. Mito e Mercadoria, Utopia e Prática de Navegar, séculos XIII-XVIII, Lisboa, Difel Difusão Editorial, 1990 , p. 118.

44 [...] fabricou o novo Pequim esta casa e lhe pôs o seu próprio nome” (cap. XCIV).

45 Tal epíteto é justificado com a "abastança", polícia e grandeza dela, como do regimento e grande governo da sua justiça e o admirável modo que tem no provimento de toda a República” (cap. CV).

46 Roma, Constantinopla, Veneza, Paris, Londres, Sevilha, Lisboa.

${ }^{47}$ Do Cairo, no Egipto, a Miacó, ou Quioto, no Japão.

48 “[...] todas estas se não podem comparar com a mais pequena coisa deste grande Pequim, quanto mais com toda a grandeza e sumptuosidade que tem em todas as suas coisas” (cap. CVII). 
A admiração utópica da sociedade exemplar, na linha de Marco Pólo, que encontra em Thomas More a contraposição longitudinal na ilha americana que tem como capital Amaurota, traduz-se na enumeração das suas principais qualidades: a sua arquitectura (soberbos edifícios), o rendimento económico, explicitado em termos hiperbólicos (infinita riqueza), a abundância superlativa dos produtos de abastecimento (sobejissima fartura e abastança de todas as coisas necessárias), a densidade populacional. Juntamente com a sua actividade comercial e náutica (gente, trato $e$ embarcaçóes sem conto), a admirável organização e funcionamento das suas instituiçôes políticas: justiça, governo, corte pacifica, estado de Tutóes, Chaens, Anchacis e Bracalóes: porque todos estes governam reinos e provincias muito grandes e com ordenados grosissimos, os quais residem continuamente nesta cidade, ou outros em seu nome, quando, por casos que sucedem, se mandam pelo reino a negócios de importância ${ }^{49}$.

$\mathrm{O}$ fascínio por tal sociedade tem, afinal, as suas fontes documentais, que sáo explicitadas, o que raramente acontece: segundo o que se escreve dela, assim no Aquesendó, de que já fiz menção, como em todas as crónicas dos reis da China ${ }^{50}$. A grandiosidade quilométrica da cidade, expressa em léguas, passa novamente pela representação hiperbólica: tem em roda trinta léguas, fora os edifícios da outra cerca de fora, de que já tenho dito um pouco e bem pouco, em comparação do muito do que ficou por dizer ${ }^{51}$. A sua dupla cintura de muralhas defensivas, com 360 portas acasteladas, no melhor exemplo da arquitectura militar, é outro dos motivos de tal fascínio. O rigoroso registo de entradas e saídas do espaço urbano indicia a tendência chinesa para a organização social.

Mas não é concebível a cultura oriental sem a expressão religiosa, com todo o fervilhar de representaçóes artísticas e cultuais. Por isso, cada dia do ano é consagrado a determinada divindade, com a respectiva celebração festiva. Daqui a superabundante edificação de templos (três mil e oitocentas casas dos seus pagodes), na sua plena actividade sacerdotal, voltada preferencialmente para o sacrifício de animais silvestres. Todavia, apesar deste fascínio, mercê do qual não se regateiam elogios à sumptuosidade de tais edifícios, a representação da pluralidade religiosa de tal povo não é compatível com a unicidade da concepção teológica do narrador. Por isso, a metáfora expressiva de tal diversidade adquire um matiz semântico marcadamente pejorativo, a do diabólico labirinto, índice de confusão ideológica, perdição e condenação ${ }^{52}$.

A concepção urbanística, mais avançada do que no Ocidente da mesma época, lembrando até o Iluminismo do século XVIII europeu, é caracterizada pela largueza de horizontes e pela nobreza de suas casas, pórticos e $\operatorname{arcos}^{53}$. De modo idêntico, a segurança dos cidadãos é garantida pela vigilância rotativa (a quartos) dos agentes

$49 \mathrm{Ib}$.

${ }^{50} \mathrm{Ib}$.

${ }^{51} \mathrm{Ib}$.

52 “[...] principalmente os das religiôes em que vivem os menigrepos e conquiais e talagrepos, que são os sacerdotes das quatro seitas de Xaca e Amida e Gizom e Canom, as quais precedem por antiguidade às outras trinta e duas deste diabólico labirinto em que o demónio se lhes mostra algumas vezes em diversas figuras, para os fazer dar mais crédito a estes seus enganos e falsidades" ( $I b$.).

53 "As ruas ordinárias desta cidade são todas muito compridas e largas e de casaria muito nobre de um até dois sobrados, fechadas todas de uma banda e da outra com grades de ferro e de latão, com suas entradas para os becos que nelas entestam e nos cabos de cada uma destas ruas estão arcos com portas muito ricas que se fecham de noite e, no mais alto destes arcos, têm sinos de vigia” ( $I b$.). 
policiais (capitão e quadrilheiros) e respectivos relatórios à câmara governamental, a fim de os magistrados (Ponchalis ou Chaens) procederem de acordo com a justiça.

A construção já antiga de 120 esteiros, com a finalidade de refrescarem a cidade, ganha em funcionalidade comunicativa e beleza visual, com a bonita soma de 1800 pontes, feitas sobre arcos de pedraria muito fortes e nos cabos colunas com suas cadeias atravessadas e poiais com encosto para a gente descansar ${ }^{54}$.

Associada às 120 praças nobres, cuja configuração não é descrita, está a instituição tradicional das feiras mensais em cada uma delas, à razão de quatro [...] por dia em todo o $\mathrm{ano}^{55}$, testemunhadas em dois meses de liberdade que gozou o narrador, em alternância ao período de cativeiro, cuja variedade de produtos (quantas coisas se podem nomear), tanto de bufarinheiros, como de mercadores ricos, e número de compradores (infinita gente), espantam os forasteiros ocidentais, pela ordem, quantidade e qualidade das peças têxteis (sedas, brocados, telas) e de vestuário (roupas de linho e de algodão e de peles de martas e arminhos), porcelanas, artefactos em ouro, prata, marfim, coral, laca, cristal, ferro e latão, especiarias (cravo, noz, maça, gengibre, canela, pimenta, tamarinho, etc), alimentos frescos (carnes, caças, pescados e hortaliças) e em conserva: andávamos como pasmados ${ }^{56}$. É esta poética do espanto e do deslumbramento ${ }^{57}$, na sequência de cronistas portugueses, como Duarte Barbosa ou Fr. Gaspar da Cruz, Tomé Pires ou Pêro Vaz de Caminha, e Garcia de Resende, que mais graciosidade confere à Literatura de Expansão.

Mas, para além desta espantosa abundância dos produtos da terra, do mar e dos homens, lembrando o mito clássico da cornucópia, ou o sonho bíblico de José do Egipto, sobre os sete anos de vacas gordas, são a ordem e a justiça, concretizadas no respeito pela pesagem dos produtos, que mais marcam o narrador ocidental ${ }^{58}$. Este elogio da justiça chinesa, representado na alegoria da Justiça e da Misericórdia ${ }^{59}$, como espectáculo de grandiosidade e realização da Verdade e do Bem, constitui o mais eloquente paradigma dos estados cristáos ${ }^{60}$. É este pensamento, tão firmemente enunciado, de que o Chinês, possuidor de uma cultura e duma ética superior à do Ocidental, que leva Jaime Cortesão a afirmar que ele "representa um conceito heterodoxo no mais alto grau, contém o germe do deísmo e é desde logo uma das mais arrojadas expressōes do humanismo universalista atingido por um português"61.

O capítulo CVII termina com a justificação pedagógica desta poética do espanto, ainda que misturada com a atribuição pejorativa do epíteto de cegos ao povo que descreve, numa perspectiva teológica e litúrgica que é timbre do narrador: digo-o para

$54 \mathrm{Ib}$.

$55 \mathrm{Ib}$.

${ }^{56} \mathrm{Ib}$.

57 Cf. Eduardo Lourenço, "O Livro do Deslumbramento", in Oceanos, No 7, (Jul. 1991, Lisboa, CNCDP), 60-61.

58 "E, além do peso que tem cada marchante por onde pesa, estão mais a cada porta outras balanças da cidade em que se torna a repesar, para ver se levam seu peso certo, para que não fique o povo enganado" (Cap. CVII).

${ }^{59}$ Cf. Cap. CXVI.

${ }^{60}$ Cf. Cap. CXIII.

${ }^{61}$ Jaime Cortesão, "Fernão Mendes pinto e o humanismo crítico", in O Humanismo Universalista dos Portugueses, Obras Completas de..., vol. VI, (Lisboa, Portugália Editora, 1965), 142. 
que se saiba quão liberalmente Deus nosso Senhor partiu com estes cegos dos bens que Ele criou na Terra, pelo que o Seu nome seja bendito para sempre ${ }^{62}$. Fazendo do exemplo de Francisco Xavier, lume no seu tempo de todo o Oriente, o estímulo para compartilhar com ele a poética do espanto, o narrador da Peregrinaçam aproxima, com ele, em grau de civilização o povo chinês e o antigo romano, bem como outros povos de excelente desenvolvimento cultural, com destaque para o primeiro: espantado, assim destas coisas, como de outras muitas excelências que nesta terra viu, dizia que se Deus alguma hora quisesse ver as ordenaçóes e os estatutos da guerra e da fazenda, por que esta gente se governava, porque tinha por sem dúvida que eram muito melhores que os dos Romanos no tempo de sua felicidade e que os de todas as outras naçóes de gentes de que todos os escritores antigos trataram ${ }^{63}$.

\section{A Carta do padre Gaspar Afonso}

A Carta do padre Gaspar Afonso ao Geral da Companhia de Jesus, em Roma, foi escrita em Évora, em 1599, dando conta ao seu superior da sua viagem ao Novo Mundo durante três anos: de 1596 a 1599.

Existem duas versóes manuscritas de tal carta: uma, extensa, na Biblioteca Pública e Arquivo Distrital de Évora, local da escrita, cota CXVI/1-16, com 168 páginas; outra, em Roma, local do destinatário, no Arquivo da Companhia de Jesus, cota Lus.106 ff. 251-270V.

Com o título extenso Viagem / da nao S. Francifco efcrita pelo P. Gafpar Affonfo hum dos oitto da Compa(n)hia, que nella hia-/mos/ anno de 1596, a primeira versão é um códice em caligrafia bem legível e em bom estado de conservação, apresentando algumas notas à margem, bem como algumas emendas e borróes. Embora não assinado, parece ser autógrafo, não repugnando, porém, a hipótese de ser apógrafo. Bernardo Gomes de Brito foi o primeiro a publicar, com algumas modificaçôes, esta versão, em 1736, ocupando o XI relato do Tomo II da sua colectânea de naufrágios, expressivamente intitulada História Trágico-Maritima ${ }^{64}$, título que, a partir de então, ficou consagrado para registar a literatura de relatos de naufrágios.

A segunda versão foi publicada, em 1984, por Giulia Lanciani ${ }^{65}$.

O Cruzeiro do Sul, metalinguisticamente explicado de acordo com o campo temático litúrgico, surge na Carta do padre Gaspar Afonso com toda a magnificência da sua corte, numa função orientadora imprescindível aos navegantes, religiosamente conotados de romeiros:

"No numero das eftrellas do outro Pólo, na propria figura, e fermofura, e feiçaó do Cruzeiro, affim chamado, pela muita femelhança que tem com o de que fe fervem as

${ }^{62}$ Cap. CVII.

${ }^{63}$ Cap. CXIII.

${ }^{64}$ Brito, Bernardo Gomes de (colector), Hiftoria Tragico-Maritima / Em que fe efcrevem chronologicamente os Naufragios que tiveraó as Naos de Portugal, depois que fe poz em exercicio a Navegaçaó da India, Tomo II, (Lisboa Occidental, na Officina da Congregaçaô do Oratorio, Livraria d'Alcobaça, 1736).

${ }^{65}$ Lanciani, Giulia, Naufragi e Peregrinazioni Americane di Gaspar Afonso, (Milano, Cisalpino-Goliardica, 1984). 
Igrejas no Officio das Trevas, fituado com fuas quadras, que faõ as duas refplandecentes eftrellas na Via Láctea, para que naó falte aos que vivem naquelle hemisferio, eftrada, nem guia de eftrellas para vir em romaria a Santiago" ${ }^{66}$.

Continuando as ilaçóes metafóricas da alegoria astral, à boa maneira barroca, o sujeito da escrita joga com a polissemia das nebulosas da constelação, numa mensagem ética oportuna:

"e em fim da mifteriofa mancha, que tem junto de si, com que parece que Deos quis avizar aos que refplandecem como eftrellas, que com qualquer defcuido em feo movimento fe cubriraó logo de manchas" 67.

Reportando os exercícios de orientação astronómica feitos em situação doméstica, não deixa o sujeito de relativizar também as imprecisóes científicas da agulha magnética ${ }^{68}$.

O calor tropical, sempre excessivo, se algumas vezes consegue contornar-se com soluçóes de relativa ultrapassagem, em outras, não permite a sua tolerância, numa canícula abrasadora. É este calor agónico comparado à perfuração das agulhas no corpo, levando o relator a ironizar o alto preço da roupa, jocosamente considerada como uma penitência e um purgatório tropicais:

"A terra he calidiffima, e affim andaó os corpos, como fe por todos feos poros eftiveffem fahindo, ou entrando agulhas. Serve efta quentura de hum bem, jà que a roupa lá he taó cara, de a efcuzar toda na cama; porque cuido eu, que quem a foffrer, por pouca, e leve que feja, fará huma fingular penitencia, e fe enfayarà bem para o Purgatorio, e fe for com caridade, e por effe refpeito, com huma fó noite de cà, pagarà muitos dias de lá" ${ }^{69}$.

É esta nova terra, encimada por novos céus, que produz a flora e a fauna exóticas, as quais desempenham papel de subido relevo no corpus textual do relato, numa nítida exposição de interesse paracientífico, a que não é alheio o valor estético-literário e humano. É a velha Europa que, vivendo o dinamismo de uma nova época, descobre, com grande entusiasmo e emoção, novos mundos que, confrontados com a estreiteza monótona do seu olhar, póem em causa a velha rotina e a mediocridade do já vivido e conhecido. Como sempre, na dialéctica do conhecer, do adaptar-se e do aprender a viver, a ambiguidade marca o registo vivencial dos testemunhos da observação directa.

Numa simbiose perfeita entre o novo e o antigo, os colonos ibéricos interpretam o tamanho diminuto das árvores, uma das maravilhas descobertas no Novo Mundo, como uma característica de pouca verdade, cristalizada num apotegma pronunciado pela rainha D. Isabel, a Católica:

“a qual ouvida pela Rainha Ifabel, refpondeo aquelle, que agora he taô celebrado apothema, ou dito naquellas partes: Que pois as arvores neffas terras tinhaó

${ }^{66}$ Ib., p. 434.

${ }^{67} \mathrm{Ib} ., \mathrm{pp} .434 \mathrm{~s}$.

68 " [...] o que tudo vay a agulha moftrando; pofto que athè agora nunca ella quis defcubrir a ninguem o fegredo, porque em humas alturas naó chega ao Norte, em outras paffa, e em outras aponta fixa, e direitamente a elle, que elles chamaó Noreftear, e Nordeftear" (Ib., p. 435).

${ }^{69} I b .$, p. 415. 
poucasmatérias, os homens feriaó de pouca verdade. E profetizou bem na opiniaó de todos os que là vivem, e na noffa, que o apalpàmos"70.

O discurso oratório, de natureza pedagógico-didáctica e finalidade ética, inscrito nos parâmetros da estética protobarroca, continua com as ilaçóes alegóricas e irónicas ao jenipapo e ao seu poder de metamorfose cromática, num labor imparável de descodificação dos enigmas da Natureza:

“ [...] a qual fruta a natureza naó fez para mais, que para em tempo de neceffidades, que fuccedem aos homens, fazer de prezente, ou com feo fumo, ou com agoa que delle fe eftila, de hum homem branco, negro [...]. Dezejey muto de achar matéria outra contraria a efta; que affim como efta tem virtude para mudar o exterior de branco em negro, affim a tiveffe a outra para mudar o interior de negro em branco, que delle fe quizeffe fervir" ${ }^{21}$.

Associada ao fruto mítico do pecado original, de acordo com uma tradição eclesiástica, a banana é figurada com as marcas visíveis da redenção universal, o Crucifixo, emblema indelével dessa memória histórica ${ }^{72}$.

O tabaco, por analogia com o vinho, então inexistente nas Índias ocidentais, apesar do nome terapêutico herva santa, é indirectamente considerado como um narcótico, a partir da desmistificação irónica das suas qualidades:

"Em lugar de vinho, que como diffe, naó ha, lhe ferve o Tabaco, a que nòs chamamos Herva Santa; ao qual fe tem por todas as Índias achadas tantas virtudes, naô fei fe reaes, fe imaginarias" 73 .

Numa concepção humanista bastante pronunciada, superando a vertente lúdica do texto, o relator admira a Sapiência divina, ao criar os cocos antropomórficos, ao serviço de adultos e crianças:

"Huma [arvore] dà huns coquinhos pouco mayores que avelans, com feo focinho, boca, olhos, e nariz, que no Brazil chamaó Vizicurum. Parece que quando a Sapiencia Divina fe andava defenfadandofe no mundo, creando nelle tantas, e taó varias efpecies de couzas, quis fazer cocos, quis fazer cocos para os homens, e coquinhos para os meninos, fem mais outra differença, que a do corpo de huns grande, e de outros pequeno, que o gofto, e fabor do miolo em todos he o mefmo"74.

Trata-se, afinal, e de certa forma, de uma nova aurea aetas, patente na fertilidade perene dos campos e das águas, sem necessidade de qualquer trabalho, mas por geração espontânea, que faz do Novo Mundo uma bênção divina:

70 Ib., p. 382.

71 Ib., p. 376.

72 " $[\ldots]$ affim a fruta como a folha he taô fermofa e deleitavel à vifta, que merecem muito perdaó, fe erraó os que por lá querem, que feja aquella a quem noffo primeiro Pay fe perdeo a fi, e a nós, como Doutores antigos querem, e dizem que foy. E de muito melhor vontade lhe dera efte perdaó, quem vir, como nòs vimos, que certa efpecie dellas, quantos cortes lhe daó, naó ao comprido, fenaó de travès, tantos Crucifixos apparecem, e à moftra, e naô pouco impreffas, para que fe lhe naô apagaffe nunca a memoria de pagar o que devia” (Ib., p. 370).

73 Ib., p. 374.

${ }^{74} \mathrm{Ib}$., p. 377. 
"e he a carne taó gorda, como aquella a quem em todo o anno nunca fe lhe feca o pafto nos campos, nem agoa nos rios, nem vio nunca arado; por que lá nenhuma couza fe lavra"75.

O próprio pau é táo inflamável que "levemente roçado accende logo o fogo". As frutas, com dupla função de aperitivo e sobremesa, abundam nas árvores, como nos jardins mais formosos, pegando de estaca e por via geracional:

"Nem foy menos liberal nas frutas, humas para fobre meza, outras para lhe dar principio; porque o primeiro he laranjas, limoens, e cidras, e affim nafcem pelo monte, como qualquer arvoredo, taô viftofas, e taó fermofas, como nos mais frefcos jardins; e as cidras de muyto mayor grandeza, que nenhumas, que eu nefta noffa terra viffe; e he a terra taó fazoavel diffo, que prendem de eftaca, tomando para iffo os filhos, ou grelos, que nafcem nas velhas"76.

No que respeita à fauna, merece particular destaque a referência ao invertebrado brasileiro, chamado Preguiça. É uma peça de grande graciosidade, fruto da ironia jocosa e de recursos como a hipérbole e a abundância de superlativos absolutos, sintéticos e analíticos:

"Alli vimos o animal Preguiça, de cuja preguiça até pouco tudo o que por cà fe terá ouvido [...]; porque fe elle fubio acima alguma hora nefta vida, ahi ha de eftar ainda: coufa he vagarofiffima e moleftiffima ver o tempo que ha mifter para andar quatro paffos, e affim naó tem neceffidade de prizaó, porque fua matéria preguiça o he baftantiffima; pois nem para fugir de ameaças de morte dà hum paffo mais apreffado; e ainda que tem muitos bons pés, e maôs, e muy deffòrmes unhas de comprimento de hum dedo, fempre leva o corpo arraftados eftendido pelo chaô"77.

A preferência pelas cobras é explicada como consequência de sua qualidade carnívora $^{78}$. Nota, porém, o relator a capacidade portuguesa em superar os tabus alimentares, aludindo, para entender tal fenómeno, à mudança climática ${ }^{79}$.

A luta predatória pelos anfíbios, cuja influência sobre o Sermão de Santo António aos peixes, do padre António Vieira, é notória, assinala-se, tanto no mar como no ar, através das metáforas como o fumo e o fogo, o dente e a unha, atribuindo-se-lhes a designação mítica de Ícaros, através de um singular sinedóquico, afectivamente conotado de "coitadinho" 80 .

75 Ib., p. 366.

${ }^{76} \mathrm{Ib} .$, p. 367.

77 Ib., pp. 330 s.

78 "Tragaó eftas hum Veado inteiro, fem fe lhe atraveffar na garganta nem hum offinho de toda fua armaçaó, e affim as vi eu por là pintadas com elles na bocca. E por fe manterem de taó boa carne, e de outras femelhantes, que pelo mato achaô, fe fazem taố faborofas ao gofto dos Índios, que quando as elles podem matar, as tem por fingular iguaria" (Ib., pp. 333 s.).

79 "E o melhor he, que os Portuguezes, ainda que nafcidos cà em Portugal, com o afco que todos temos a Cobras, e a Lagartos, mudado o clima, mudaó tambem a natureza, e perdem todo efte affombramento, e achaô em fua carne tanto gofto, como os Índios" (Id., p. 334).

80 "He efta e defarmada turba de Voadores perfeguida no mar de grandes, que em toda a parte fe querem manter dos pequenos; e no ar (que a natureza quando fe lhes deo azas, lhes affinou por couto) das verdadeiras aves que os defconhecem, e naó querem admittir, nem receber taes moradores em feo alimento, nem agazalhar em fua caza. E affim fugindo os coitadinhos dos grandes, a quem elles fugiraó da bocca, fabem quaó feguindo por baixo com tanta ligeireza e velocidade, como elle voa por cima, athè que arremetidas as azas lhes cahe a pique na bocca" (Ib., p. 321). 
Os tubarôes, ainda que "feros e carniceiros", têm o condão de "com fua vifta, alliviar a moleftia dos navegantes, fem quererem por feo ferviço mais jornal que a comida" 81 . E, numa espécie de relação feudal, consentem que os pobres romeiros se sustentem das migalhas de sua farta mesa ${ }^{82}$.

Por outro lado, artistas do Oceano, os cetáceos divertem os náufragos convalescentes no Colégio da Baía com suas piruetas graciosas, referência que confere ao texto uma interessante descompressão, através de um ritmo descritivo de autêntico bailado ${ }^{83}$.

Animal guerreiro, dotado pela Mãe Natureza com as armas defensivas mais completas, o tatu espanta o relator quanto ao sentido profundo deste táo versátil dote:

"Vimos outro animal, a quem os Brazis chamaó Zatûs, ao qual a natureza armou de coçolete, efpaldar, coxetas, manoplas, a todas as mais peças com que a arte depois aprendeo a armar hum homem de ponto em branco; e fe Deos, e a natureza naô fazem couza de balde, como Ariftoteles diz, bem entrar em feos Problemas efte: Porque a natureza armaria a efte animal com tais armas? Ou porque lhe eftimaria, ou guardaria tanto a vida, para lhe fegurar tanto nas garras?" 84 .

A metamorfose das borboletas em pássaros e do cão do Japão em peixe sugere implícita e sub-repticiamente a questão da metempsicose, tão expandida no Oriente, embora, apoiado em S. Basílio e S. Gregório, o narrador se limite a transitar explicitamente entre a leitura científica de tal fenómeno e a leitura moral da ascese humana ${ }^{85}$.

Produto do espanto face a novos fenómenos naturais, o relator destaca, ainda, a liturgia dos bugios, cuja linguagem gostaria de descodificar, exaltando as virtudes do orador nato.

"Das letras, e habilidades dos Bogios fe fabe cà muito pouco, e muito menos de feos Sermóes, e exhortaçoens. Folgara eu muito de entender o feo Latim, porque me naó houvera de efcapar prégaçaó, para faber fobre que matéria tratara o pregador, e que virtudes, perfuadia a feos ouvintes, e a delicadeza de feos conceitos. Só fe fabe fer a peffoa

81 "Nem acrefcentaó menos prazer por fua parte os Tubaroens, peixe fero, e carniceiro, os quaes tem por devoçaó naô fe apartar da Nao enquanto eftà em calma, ou corre com pouco vento, para com fua vifta alliviar a molleftia dos navegantes, fem quererem por feo ferviço mais jornal, que a comida” (Ib., p. 321).

82 "E para effe effeito de fegurança fua nunca fe lhes fahem das còftas contrapoftos à bocca que vay por baixo; e sentem-fe elles taó obrigados por efta efmola (virtude propria de pobres, fer conhecidos, e agradecidos) que prezo elle fe prendem elles [...] tendo por acto de muito primor [,,,] a quem feguîraó no profpero, acompanhar tambem no adverfo, e morrer com quem viveraô” (Ib., p. 323).

83 "[...] e o gaftaó em continuas feftas, faltos, e danças [...]. Do que nos nòs logràmos bem em quanto a convalescenças das doenças paffadas naó deixava olhar para outros livros, e precer-lhes a ellas, que o fazem com tanto ar, e graça, que para que fe naô perca volta fua que naó feja vifta, tanto que de là do fundo chegaó à fuperficie da agoa; e captada affim a attençaó aos olhos fe vay levantando e empinando muy direita para o Ceo, athè que impedindo-lhe a natureza hir por diante, e tomar mais do elemento alheyo, dà com aquella graó torre de carne ou peixe daveffo, e a eftende fobre a agoa com huma fonora pancada” (Ib., p. 329).

${ }^{84} \mathrm{Ib}$., p. 331.

85 "Vimos mais huns paffarinhos, que depois de fe enfadarem de fer Borboletas, e de viver em taó baixo e taô imperfeito eftado, com dezejo de fubir, e valer, que athè nos brutos parece que reina, fe paffaó a outro mais alto, e mais perfeito, fazendo-fe paffarinhos muito lindos, e de cores mais louçans [...]. Cuja metamorfofe, ou tranformaçaó crerà facilmente quem crer a do Caó do Japaó, que enfadado tambem de fer Caố na terra, fe vay tambem a feo parecer melhorar, e fazer peixe no mar, que eu vi, e tive nas maós com metade da converfaó jà feita em Lisboa, que os noffos Padres de lá mandàraó no anno de 1576 [...], o que parece fer mais; porque aquelles naô mudaó mais que a natureza: e efte a natureza, e elemento" (Ib., pp. 331 s.). 
do prègador mais reverendo, e fer acompanhado ao pulpito, por maior honra e autoridade, de dous acolitos, que fervem, durante o Sermaô, de lhe eftarem alimpando a baba, que com o muito zelo, fervor, e corrente de palavras lhe cahe da bocca, fem faltar mais que vestir-lhe no cabo huma camiza quente, por lhe naô dar algum ar; afora outras mil couzas, fuas defta qualidade, que podem bem inquietar o fizo de feos ouvintes" 86 .

Entre realidade e mito a distância é relativamente curta. É verdadeiramente um espaço diferente do europeu, cruzado entre o mítico e o real, que se desvenda aos olhos embevecidos dos Portugueses quinhentistas, como que dando a razão a Montaigne e aos outros humanistas coevos, numa confirmação dos "novos céus e nova terra”, anunciados no Livro do Apocalipse ${ }^{87}$.

O símile da árvore do Paraíso, na bivalência das suas características, numa dialéctica dos sentidos, atracção estética versus repulsa nutricional (distrofia), é bem uma alegoria das coisas humanas, do objecto a conquistar pelo homem, já simbolizada mo mito genesíaco do pecado:

"Debaixo de huma arvore nos affentàmos ao longo do mar huma tarde, de que há grande copia entre aquelle arvoredo, que nas folhas, fruta, e cheiro, fe eftivera entre maceiras de algum pomar, as colhera, e comera por taes qualquer peffoa, e comêramos nòs também por ventura, fenaó eftiveramos jà avizados, que daquellas maçans fenaô logravaó mais fentidos, que a vifta, e o cheiro, e naó o gofto, por finiffima peçonha. Reprefentou-fe-me alli Eva, como fe eftiveffemos ambos olhando para a arvore, e para a fruta, parecendo-nos a ambos Pulchrum oculis, afpectuque delectabile. Só houve differença em naó confentir eu com a tentaçaó de comer, que tambem tinha, por eftimar mais a vida do corpo, do que ella eftimou a da alma, julgando o contrario do que ella julgou, que ainda que tinha tudo o mais, toda-via Non erat bonum lignum ad vefcendum" 88 .

Esta riqueza mitológica, cujas virtualidades o sujeito da escrita não se cansa de explorar, é sumariada na reflexão que faz, a propósito do mito cosmogónico que assinalou:

"Parece que naó tem ainda a natureza das couzas perdido por cà nada daquelle vigor, com que Deos as creou; porque fó esfta refpofta pòde tirar o efpanto aos que de cà vaó, e a pergunta, que fazem, onde fe pòde achar arvore taó groffa, taó comprida, e taó uniforme?" 89 .

\section{Conclusão}

Os Lusiadas, a Peregrinaçam e a História Trágico-Marítima, na especificidade literária de cada qual, são três das mais significativas representaçóes do mundo utópico renascentista português e europeu.

\footnotetext{
86 Ib., pp. 332 s.

87 Cf. Apoc., XXI, 1.

${ }^{88}$ Ib., pp. 418 s.

89 Ib., p. 419.
} 
A Ilha de Vénus figura um espaço imaginário, simbólico da glorificação épica dos grandes feitos humanos, enquanto a cidade de Pequim é guindada à excelência modelar da civilização e da felicidade humanas e o Novo Mundo recorda a hesiódica aurea aetas, a sociedade edénica do otium.

Afinal, confrontado com a dura realidade do quotidiano, o homem sempre carece de um espaço utópico, ou mesmo eutópico, não apenas como expressão de uma sentida evasão ou alienação, mas também como satisfação natural da ansiada plenitude. 


\section{Série}

\section{Documentos}

Imprensa da Universidade de Coimbra

Coimbra University Press

2009

- $\mathrm{U}$

C • 